\title{
Assessment of Energy Technology to Abate Air Pollution Emissions in China ${ }^{\dagger}$
}

\author{
Aijun LI*, Hiroyuki Shibusawa*, \\ Yuzuru MiYATA* and Makoto YAMAGUCHI*
}

\begin{abstract}
This paper attempts to empirically analyze the interregional repercussion of collecting environmental tax to introduce abatement technology for the case of China's air pollution problem, by applying a dynamic interregional CGE model. For this purpose, the possible future of energy technology development is forecasted by a series of scenarios. Then the short-term low scenario is simulated by assuming all sulfur tax will be paid back to local region to introduce desulfurization technology. Given several desulfurization technologies used in current secondary energy sector, each technology's affordability, environmental impacts and economic effects are numerically examined over 20 years. Finally, these technologies are assessed for China's sustainable development.
\end{abstract}

\section{Introduction}

China's economy has been rapidly growing over 20 years. But such rapid economic development started from low level; there are many deficiencies in the economy. Under this situation, today China has become a major country in the world in terms of energy production and consumption. Since coal plays a larger role than it does in most other countries, energy is recognized as one of the major sources of environmental degradation. Sulfur dioxide and soot are the major air pollutants. Acid rain is extremely serious. In developed countries, sulfur dioxide emission problem was solved in 1980s, since huge public fund has been put into introducing desulfurization technologies. But China is a large developing country, government cannot subsidize enough into environmental protection; abating sulfur dioxide emission seems too expensive. How to use market-based environmental policy to create a clean energy market seems very urgent in China. In this study, sulfur tax is assumed to be imposed on all fossil fuel users. About the introduction of sulfur tax, this paper tries to combine China's current environmental policy with developed countries' experience. With the lightened interest in the environmental problem, pollution charges and fines have been imposed in China. To cope with serious acid rain problem, an environmental policy, "Charges on $\mathrm{SO}_{2}$ Discharges", has been implemented on the thermal power and heating supply sectors ${ }^{[7]}$. In addition, with unsolved acid rain problem for long period, many people have already begun to doubt current environmental policy's effectiveness ${ }^{[3]}$. From the experiences of the OECD countries, environmental tax has more advantages than pollution

† The earlier version of this paper was presented at the 39th Annual Meeting of the Japan Section of the RSAI. We would like to thank Prof. Ouchida, Y. and two anonymous referees for their helpful comments and suggestions.

* Toyohashi University of Technology 
charges and fines in environmental management. Therefore, this paper uses the rate of sulfur emission charge in current secondary energy sector as the rate of sulfur tax to the whole economy, which is introduced as ad valorem tax.

Moreover, the interregional imbalanced development of China also has become a hidden danger of social stability. With the rapid growth of China's economy, more and more labor force and capital investment have been concentrated in eastern coastal areas, despite of the central government's western area development program. This has caused western region' s over-poverty phenomenon together with eastern region's over-pollution phenomenon. As introducing environmental regulation to China's economy, how will such regional disparity be changing? As we have known ${ }^{[4]}$, after the introduction of sulfur tax, in each region and in each economic sector, the low sulfur fuel (mainly distribute in north-eastern China) will be preferred to substitute high sulfur fuel (mainly distribute in south-western China). Such interregional energy transaction may induce the repercussive effects on the whole economy. But there still remain several problems. The first is: if sulfur tax is used to introduce desulfurization technology, how will the economic and environmental system be changed? The second is: whether is the sulfur tax enough to introduce desulfurization technology? The third is: there are several desulfurization technologies in secondary energy sector that can be chosen, including China's own technology and foreign countries' technology, how can we choose these desulfurization technologies? Therefore, in this study, a dynamic interregional CGE model is developed to analyze the effects of using environmental tax to introduce abatement technology, by calculating the equilibrium of each year, thus the intermediate impact can be distinguished from the long run effects.

\section{Classification of Regions and Industries}

Since our CGE model includes multi-region and multi-sector, we need to classify region and industry at first. Taking into account the geographical distribution of the energy resources, China is divided into seven regions as shown in table 1 . Let $S=\{1,2,3,4,5,6,7\}$ denotes an index set over regions excluding the foreign sector, although it is treated as the eighth region.

There are 9 industries in each region as depicted in table 2. Each industry produces

Table 1 Classification of Regions

\begin{tabular}{ll}
\hline \multicolumn{1}{c}{ Regions } & \multicolumn{1}{c}{ Provinces and Cities } \\
\hline 1. Dongbei & $\begin{array}{l}\text { Liaoning, Jilin, and Heilong- } \\
\text { jiang } \\
\text { Beijing, Tianjin, Hebei, Shan- } \\
\text { dong, and Inner Mongolia }\end{array}$ \\
3. Huabei & $\begin{array}{l}\text { Shanghai, Jiangsu, and Zhejiang } \\
\text { Fujian, Guangdong, and Hainan }\end{array}$ \\
5. Huanan & $\begin{array}{l}\text { Shanxi, Henan, Anhui, Hunan, } \\
\text { Hubei, and Jiangxi }\end{array}$ \\
6. Xibei & $\begin{array}{l}\text { Shaanxi, Qinghai, Gansu, Nin- } \\
\text { gxia, and Xinjiang }\end{array}$ \\
7. Xinan & $\begin{array}{l}\text { Sichuan, Guizhou, Yunnan, } \\
\text { Guangxi, and Tibet } \\
\text { rest of the world }\end{array}$ \\
\hline
\end{tabular}

Table 2 Classification of Industries

\begin{tabular}{cl}
\hline No. & \multicolumn{1}{c}{ Sectors } \\
\hline 1 & agriculture \\
2 & primary energy industry \\
3 & material industry \\
4 & secondary Energy Industry \\
5 & processing and manufacturing indus- \\
& try \\
7 & construction Industry \\
7 & transportation and telecommunication \\
8 & industry \\
9 & commerce \\
\hline
\end{tabular}


commodities/services inputting primary factors (capital and labor) and intermediate commodities. Products in different regions are assumed to be qualitatively differentiated each other. Let $J=\{1,2,3,4,5,6,7,8,9\}$ denotes an index set over industries groups. Moreover $J^{\prime}=\{1,2,3,4,5,6,8,9\}$ denotes an index set over sectors excluding the transportation and telecommunication industry 7 .

\section{Model Overview}

Figure 1 shows the basic structure of the model. Since in China, most companies cannot pay environmental protection cost themselves, here government is assumed to collect environmental tax, then arranges how to invest into abatement technologies. Thus this study is based on that government can gain complete information.

An interregional computable general equilibrium model (ICGE) was previously constructed to analyze China's energy supply and demand problem ${ }^{[2]}$. Then we extended this model to examine the effectiveness of environmental taxes ${ }^{[4]}$. The current version of this model is extended to study the possibility of introducing abatement technology by environmental taxes. Since our model is a fairly standard interregional CGE model, here we only describe it briefly. In our model, different regions are linked together by transportation services. The foreign sector and other regions are linked together by importing and exporting. The transportation services are treated as the derived demand. Commodities produced in different regions are treated as qualitatively different. The economy is endowed with primary factors: labor and capital. Labor is mobile among industries and regions; capital is mobile across industries but immobile across regions. China's economy consists of 72 commodity markets ( 9 sectors $\times 8$ regions) and 8 production factor markets ( 7 capital and 1 labor). Perfect competition is assumed in each market.

Our model aims to examine the relationship between economic growth, energy use and $\mathrm{SO}_{2}$ emissions. Therefore, the main focus is on the primary energy sector and secondary energy sector. In primary energy sector, natural gas is neglected here, two sources of fossil fuel-crude oil and coal are distinguished. In secondary energy sector, one source of nonfossil energy, electricity, and six sources of fossil fuel : fuel oil, diesel oil, gasoline, kerosene, $L P G$ and $L N G$ are distinguished. We investigate the final use of each secondary energy product by region and sector, and find that each type of secondary energy products has its special commercial use, such as: fuel oil cannot be used in household sector; the result shows the composition of secondary energy products' consumption is quite different by region. Among secondary energy products, electricity and kerosene do not emit any $\mathrm{SO}_{2}$ when they are used as energy. But other secondary energy products emit $\mathrm{SO}_{2}$ when they are burned; we assume that their sulfur contents are not related to their producing regions. However, in China, the sulfur content of coal is quite different by its producing region ${ }^{[6]}$, we consider this characteristic in our study. Taking account of the difference in the quality of energy resources and the difference in the composition of energy uses in each economic sector, we estimate China's $1992 \mathrm{SO}_{2}$ emission factors by region and sector respectively, referring to China's Energy Statistical Yearbook and some energy engineering papers.

This version of our interregional CGE model has a simple recursive structure, in which the growth rate of labor and the growth rate of capital by region within different periods are 
Interregional Transaction of Intermediate Inputs

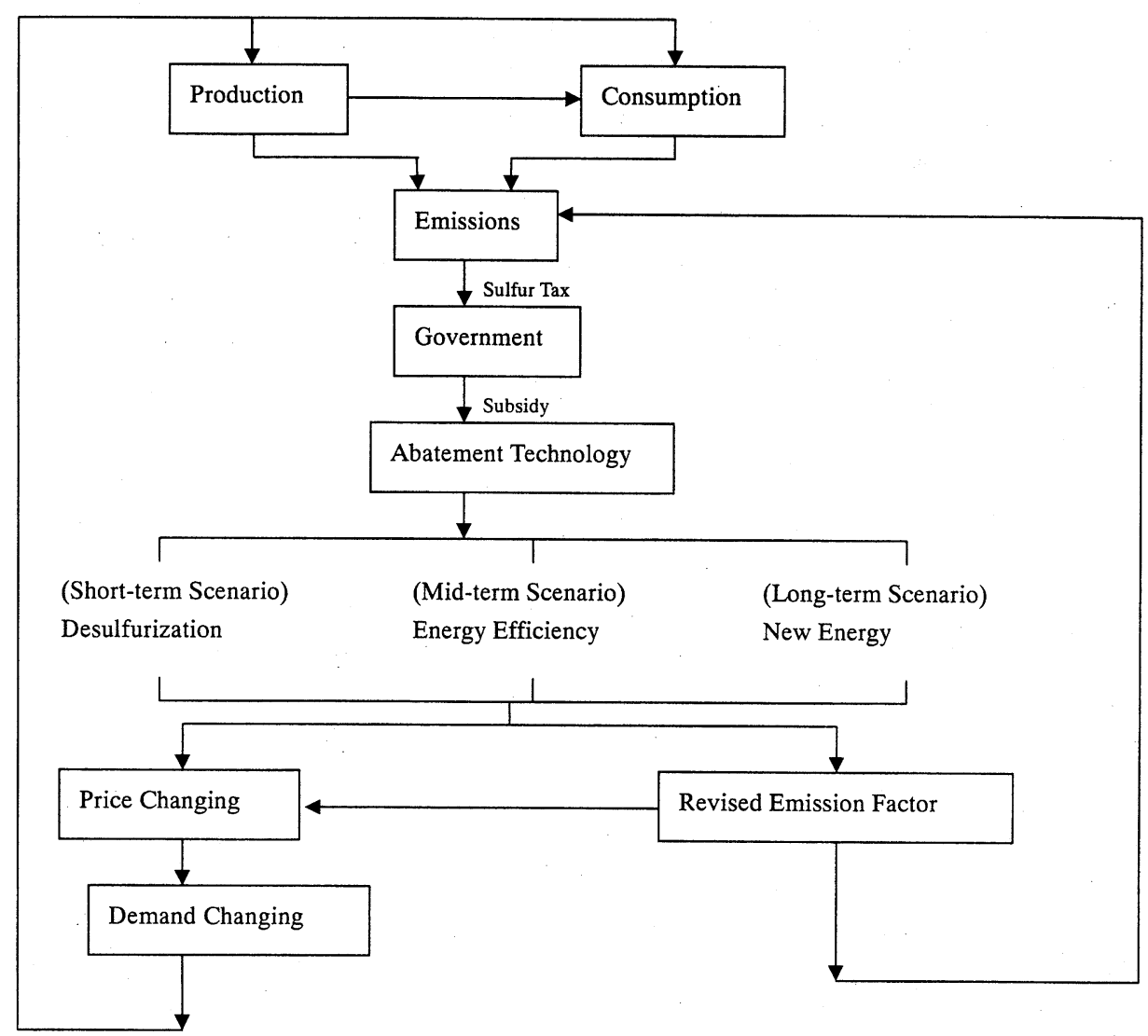

Figure 1 Basic Structure of the Model

given according to the government forecast of China's economy, the emission factors are revised according to the type of energy technology in each period. However, industrial sector's investment decisions are not modeled and investment is computed residually, such disposal way has been used in the literature ${ }^{[1]}$. 1992 is set up as the benchmark year. This model is currently simulated over the 1992-2012 year. The evolution over time of the economy can be described as a sequence of single-period static equilibrium.

\subsection{Single-period Equilibrium}

We assume the producer plans to maximize his profits in each period $t$, production is seen as a physical process that can be repeated in every period provided that intermediate inputs, labor, and capital are available. We describe the technology in each period $t=1,2, \cdots, T$ by constant returns to scale. The production function for industry $j \in J$ in region $s \in S$ in each period $t$ takes the nested Leontief-Cobb-Douglas form. Consumers are assumed to share an aggregate single utility function. We assume that the utility function takes the nested CobbDouglas form. Maximization of the temporal utility function subject to the temporal budget constraint generates the household demand function for commodity $i$ in region $r$. The 
temporal demand for transportation services is derived from shipment of commodities among regions in each period $t$. It is assumed that the transportation cost is paid to the transportation sector in the origin region. Assuming that in each period $t$, the transportation sector has the same type of production function as other industries, the cost minimization problem subject to the constraint of transportation services yields the temporal demand functions for capital, labor, and intermediate commodity $i$. We assume that government collects direct, indirect and environmental taxes from households and industries in all the regions in each period $t$, then government uses the environmental taxes to subsidy the abatement technologies in period $t+1$. Given a rate of government consumption and income transfer ratio, the government consumption and income transfer to households are calculated. Government savings are defined as the difference between the revenues and expenditures of the government. In each period $t$, household șavings, government savings, savings of foreign sector and capital depreciation determine the total investment expenditure. Minimization of the investment cost leads to temporal demands for production commodities. The foreign sector obtains its income from China's imports, and then it expends the income on China's exports. The temporal savings of foreign sector are defined as the difference between imports and exports in each period $t$. $\mathrm{SO}_{2}$ emissions are assumed to be proportional to intermediate and final consumption of the primary or secondary energy sector's products, $\mathrm{SO}_{2}$ tax is imposed on intermediate and final inputs of energy products in every industry as advalorem tax. In each region and in each period, equilibrium is characterized as a set of prices of goods and primary factor that equate supply and demand in all corresponding market.

\subsection{Multi-period Evolution}

This is a recursive model. The evolution in this model originates from two sources: the reduction of emission factor, the growth of capital accumulation and labor. The growth rate of capital supply and the growth rate of labor supply are shown in table 3 and table 4 . While the reduction of emission factor will be described afterwards, the growth of capital accumulation and labor can be calculated as follows:

\subsubsection{Capital Accumulation}

$$
K^{s}(t+1)=K^{s}(t)\left(1+\rho_{K}^{s}(t)\right)
$$

$K^{s}(t)$ : capital accumulation in region $s$ and period $t, \rho_{K}^{s}(t)$ : growth rate of capital supply in period $t$;

Table 3 Growth Rate of Capital Supply

\begin{tabular}{lrc}
\hline & $1992-1999$ & $2000-2011$ \\
\hline Huabei & $11.72 \%$ & $10.80 \%$ \\
Dongbei & $7.58 \%$ & $13.51 \%$ \\
Huadong & $15.73 \%$ & $12.95 \%$ \\
Huanan & $16.30 \%$ & $8.98 \%$ \\
Huazhong & $10.04 \%$ & $12.06 \%$ \\
Xibei & $7.94 \%$ & $16.19 \%$ \\
Xinan & $9.74 \%$ & $11.92 \%$ \\
\hline
\end{tabular}

Source : estimated according to China's Government Report, 2001

Table 4 Growth Rate of Labor Supply

\begin{tabular}{rc}
\hline $1992-1999$ & $1.139 \%$ \\
\hline $2000-2005$ & $0.724 \%$ \\
\hline $2005-2010$ & $0.685 \%$ \\
\hline $2010-2012$ & $0.495 \%$ \\
\hline
\end{tabular}




\subsubsection{Labor Augmenting}

$$
L(t+1)=L(t)\left(1+\rho_{L}(t)\right)
$$

$\rho_{L}$ : growth rate of labor in period $t, L(t)$ : labor supply in period $t$.

\section{Forecast of Energy Technology Development in China}

To cope with serious air pollution problem, undoubtedly, a lot of advanced energy technologies should be introduced to China's economy according to China's specific situation. Since it is very common to use 'scenarios' to forecast possible future about the development of energy technology, here we conceive a series of scenarios to develop energy technology for abating air pollution, improving energy efficiency and making energy supply reliable in China, the principle to make such 'scenarios' is to satisfy the growth of energy demand while meeting environmental regulations at low cost.

\subsection{Short-term Scenario}

In the short-term, it would be expensive to write off existing energy supply facilities or to deploy major new technologies on a large scale; the goal of this scenario is to meet existing and emerging environmental regulations, which means to install desulfurization facilities to control $\mathrm{SO}_{2}$ emission at existing power supply facilities.

Short-term Low Scenario :

Desulfurization technology has been widely introduced into secondary energy sector.

Short-term High Scenario :

Desulfurization technology has been widely introduced into other industrial sector.

\subsection{Mid-term Scenario}

In the mid-term, the goal of this scenario is to develop low-cost, super clean energy facilities, with efficiency $50 \%$ higher than today's average efficiency. Higher energy efficiency will reduce emissions at minimal costs. If local condition is possible, interfuel substitution also can be considered to provide clean energy at low cost.

Mid-term Low Scenario :

Cogeneration technologies, such as combined heat and power (CHP) and integrated gasification combined-cycle $(I G C C)$, have been widely used at secondary energy supply facilities.

Mid-term High Scenario :

Substitution of high-pollutant fossil fuels by low-pollutant fossil fuels, such as increasing the use of natural gas to substitute some portion of coal, can be applicable at least in the heavily polluted region.

\subsection{Long-term Scenario}

In the long-term, a large proportion of existing installations may be replaced, and a much wider range of technologies may be available including many technologies which are in prototype or which at least can be constructed on current knowledge but have not yet been commercially developed. The goal of this scenario is to develop low-cost, zero emission 
power supply facilities with efficiencies close to double that of today's facilities.

Long-term Low Scenario :

Zero emission technology, such as advanced fuel cell, can be commercially utilized.

Long-term High Scenario :

Non-fossil fuel technology, such as solar photovoltaic power, can be commercially utilized.

Since the limited time and scarce information, in this study we only simulate the shortterm low scenario for introducing desulfurization technology in secondary energy sector. In China, the secondary energy sector is the biggest contributor of $\mathrm{SO}_{2}$ emission; it emits about $35 \%$ of $\mathrm{SO}_{2}$ pollution among the total industrial sectors. Given the abundant reserves of coal, the continued role of coal as a fuel to meet rising energy demands and economic growth rates is undoubted. How to develop clean-coal technology for the future is a project that will be unavoidable in China.

\section{Performance Parameter of Five Desulfurization Technologies}

Until now, a lot of desulfurization technologies have gained high sulfur removal efficiency, but we cannot determine which desulfurization technology has greater developing potential only by its environmental effect, we also need to consider its economic impact. In China, the research of desulfurization technology has been mature, but the application of desulfurization technology is at beginning. Here we give five typical desulfurization technologies $^{[5]}$, which have been used in secondary energy sector in China :

(Technology 1) LIMB : limestone injection multistage burner ;

(Technology 2) LIFAC : limestone injection into the furnace and activation of unreacted Calcium ;

(Technology 3) SDA : spaying-drying air flow;

(Technology 4) LstWG : limestone white-gypsum;

(Technology 5) PAFP : phosphate ammonium fertilizer process.

Technology transfers from developed countries to China have been existed many years ago. Among all these technologies, only PAFP technology is developed by China's own research institute, other technologies are entirely introduced from foreign countries. Direct government financial support for technology transfer now plays an important role in China. International organizations' support is also important. But such support seems not enough to satisfy China's energy consumption growth. LstWG technology seems being most commonly used in developed countries. But the economic condition, environmental situation,

Table 5 Performance Parameters of Five Desulfurization Technologies

\begin{tabular}{ccccc}
\hline $\begin{array}{c}\text { Desulfurization } \\
\text { Technology }\end{array}$ & $\begin{array}{c}\text { Removal Efficiency } \\
(\%)\end{array}$ & $\begin{array}{c}\text { Capital Cost } \\
(\text { Yuan/kW })\end{array}$ & $\begin{array}{c}\text { Operation Cost } \\
\left(10^{-3} \text { Yuan/kWh }\right)\end{array}$ & $\begin{array}{c}\text { By-product } \\
\left(10^{-3} \text { Yuan/kWh }\right)\end{array}$ \\
\hline LIMB & 50 & 122 & 10 & 0 \\
LIFAC & 80 & 135 & 10.4 & 0 \\
SDA & 85 & 168 & 13 & 0 \\
LstWG & 95 & 324 & 18.2 & 11.8 \\
PAFP & 95 & 391 & 24.3 & 34.9 \\
\hline
\end{tabular}

Source: from Electrical Technology (in Chinese), by Chinese Thermal Power Research Institute, 1992 
and distribution of natural resource in China are quite different with other countries, whether foreign technology can be better than China's own technology still need to be doubted.

Each technology's cost and efficiency have been shown in table 5. Note that for each technology, as the removal efficiency becomes higher, the cost also becomes higher. Especially, the removal efficiency of technology $L s t W G$ and technology PAFP are same, but the cost of PAFP technology seems higher while its by-product's price is also higher. We cannot distinguish which technology is better from this table. Therefore, we construct a dynamic interregional CGE model to assess these desulfurization technologies. Another noticeable problem is, the price of desulfurization technology probably will be changed in the future. However, as desulfurization technology itself has been popularized in the industrialized world, its price seems relatively stable now; therefore we assume its price is unchanged in this study.

\section{Emission Abatement Processes}

As mentioned above, we need to examine each desulfurization technology's effects by a dynamic interregional CGE model. First, about the five typical desulfurization technologies described above, we calculate the revised emission factor in each period respectively as follows :

\subsection{Sulfur Tax}

$\mathrm{SO}_{2}$ emissions due to consumption of primary energy products in period $t$ are given as follows :

$$
E S_{2 i}^{r s}(t)=\xi_{2 i}^{r s}(t) \times x_{2 i}^{r s}(t)
$$

where, $E S_{2 i}^{r s}(t)$ : volume of $\mathrm{SO}_{2}$ emissions in sector $i$ of region $s$ due to consuming primary energy produced in region $r$ in period $t, \xi_{2 i}^{r s}(t)$ : composite $\mathrm{SO}_{2}$ emission factor in sector $i$ due to the consumption of primary energy products in sector 2 from region $r$ to region $s$ in period $t, X_{2 i}^{r s}(t)$ : intermediate input of primary energy (commodity 2 ) from region $r$ to industry $j$ of region $s$ in period $t$.

$\mathrm{SO}_{2}$ emissions due to consumption of secondary energy products in period $t$ are given as follows :

$$
E S_{4 i}^{r s}(t)=\xi_{4 i}^{r s}(t) \times x_{4 i}^{r s}(t)
$$

where, $E S_{4 i}^{r s}(t)$ : volume of $\mathrm{SO}_{2}$ emissions in sector $i$ due to the consumption of secondary energy products from region $r$ to region $s$ in each period $t, \xi_{4 i}^{r s}(t)$ : composite $\mathrm{SO}_{2}$ emission factor in sector $i$ due to the consumption of secondary energy products from region $r$ to region $s$ in each period $t, X_{4 i}^{r s}(t)$ : intermediate input of secondary energy (commodity 4) from region $r$ to industry $j$ of region $s$ in each period $t$.

The total $\mathrm{SO}_{2}$ emissions in period $t$ are given as follows:

$$
E S_{i}^{r s}(t)=E S_{2 i}^{r s}(t)+E S_{4 i}^{r s}(t)
$$

where, $E S_{i}^{r s}(t)$ : total volume of $\mathrm{SO}_{2}$ emissions in sector $i$ from region $r$ to region $s$ in each period $t$.

Then we can calculate sulfur tax in region $s$ and period $t$ as follows : 


$$
T A X S^{s}(t)=\sum_{r=1}^{7} \sum_{i=2,4} \sum_{j=1}^{9} t s_{i j}^{r s}(t) \times \xi_{i j}^{r s}(t) \times x_{i j}^{r s}(t)
$$

where, $t s_{i j}^{r S}(t): S_{2}$ tax rate imposed on intermediate inputs of energy products in period $t$, $\xi_{i j}^{r s}(t)$ : composite $\mathrm{SO}_{2}$ emission factor in period $t$ in sector $j$ due to the consumption of energy products in sector $i$ from region $r$ to region $s, x_{i j}^{r_{S}}(t)$ : in period $t$, intermediate energy input produced in region $r$ and sector $i$, but consumed in region $s$ and sector $j$.

\subsection{Budget Constraint of Introducing Desulfurization Technology}

Let each region's sulfur tax be paid back to this region itself to introduce desulfurization technologies. Assuming that all by-products of desulfurization technology can be sold in time, then how much proportion of thermal power units can be installed with desulfurization facilities in secondary energy sector can be calculated as:

$$
\delta_{4}^{s}(t+1)(k)=T A X S^{s}(t) /\left[U C(k) \times N I C^{s}(t+1)+(U O(k)-U B(k)) \times P G^{s}(t+1)\right]
$$

where, $\delta_{4}^{S}(t)(k)$ : proportion of thermal power units that can be installed with facilities of desulfurization technology $k$ in secondary energy sector in period $t, U C(k)$ : capital cost of desulfurization technology $k, N I C^{s}(t)$ : newly installed capacity in region $s$ and period $t$, $U O(k)$ : operational cost of desulfurization technology $k, U B(k)$ : by-products' price of desulfurization technology $k, P G^{s}(t)$ : thermal power generation in region $s$ and period $t$.

If assuming all by-products cannot be sold out, we let $U B(k)=0$.

\subsection{Modified Emission Factor}

Modified emission factor by introducing desulfurization technology $k$ in secondary energy sector in period $t$ is defined as follows :

$$
\xi_{4 j}^{r s}(t)(k)=\left(1-\delta_{4}^{s}(t)(k)\right) \times \xi_{4 j}^{r s}(t)(k)+\delta_{4 j}^{r s}(t)(k) \times \vartheta(k) \times \xi_{4 j}^{r s}(t)(k)
$$

where, $\vartheta(k)$ : removal efficiency of desulfurization technology $k$.

\section{Simulation Analysis}

In this study, we assume that $200 \mathrm{Yuan} / \mathrm{SO}_{2}$-ton tax is imposed on energy consumption in every economic sector, and this tax rate is according to the current charge rate of $\mathrm{SO}_{2}$ emission imposed on the thermal power plants and heat supply industry in China. In order to compare different desulfurization technologies' effects, eight cases are set as follows :

Base case : sulfur tax is not used; case 1 : sulfur tax is used to introduce desulfurization technology 1 ; case 2 : sulfur tax is used to introduce desulfurization technology 2 ; case 3 : sulfur tax is used to introduce desulfurization technology 3 ; case $4 \mathrm{a}$ : sulfur tax is used to introduce desulfurization technology 4 , assuming all its by-products can be sold out ; case $4 \mathrm{~b}$ : sulfur tax is used to introduce desulfurization technology 4, assuming all its by-products cannot be sold out; case 5a: sulfur tax is used to introduce desulfurization technology 5 , assuming all its by-products can be sold out; case $5 \mathrm{~b}$ : sulfur tax is used to introduce desulfurization technology 5 , assuming all its by-products cannot be sold out.

The simulation result is analyzed as follows: 


\subsection{Technology's Affordability}

As shown in figure 2, since each region's environmental and economic condition is different, the desulfurization technologies' introduction rate is quite different by region after 20 years. It shows, in those comparatively undeveloped regions such as region 1 , region 2 , region 5 , and region 6 , only by technology 5 a, the introduction rate can reach $100 \%$ after 20 years; by other technologies, in all above regions, the introduction rate cannot reach $80 \%$ after 20 years. In those comparatively developed regions, such as region 3 and region 4 , sulfur tax seems not enough to introduce desulfurization technologies. In region 3 , besides technology 5a, no any technology's introduction rate can even reach $30 \%$. In region 4 , using technology 5 a can make the introduction rate reach $77 \%$ after 20 years; by using other technologies, it even cannot reach $40 \%$. Region 7 is the most undeveloped; in this region, by using technology 5 a, technology 2 and technology 1, the introduction rate can reach $100 \%$; by using technology 3 and technology $4 \mathrm{a}$, the introduction rate also can be over $80 \%$. Figure 3 shows the desulfurization technologies' introduction rate is quite different by region and

Unit: \%o

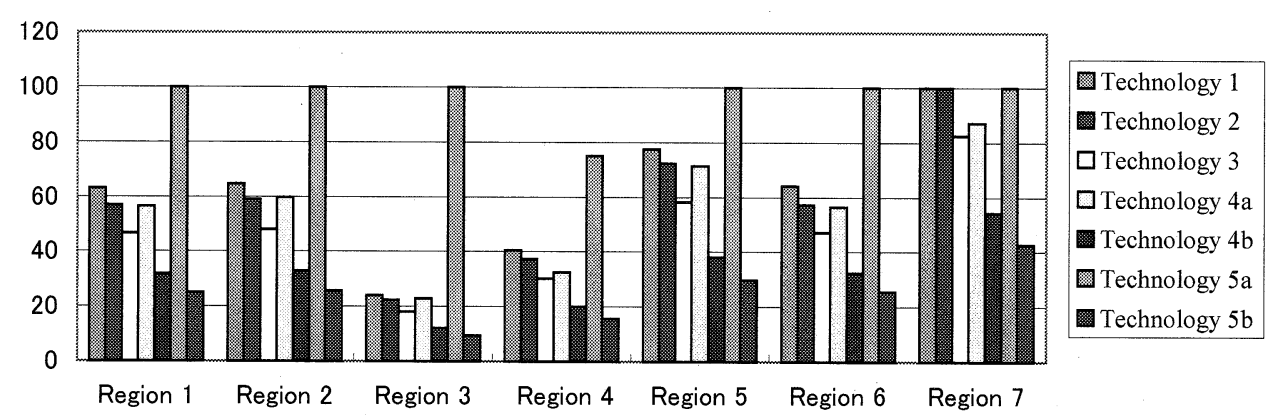

Figure 2 Introduction Rate of Desulfurization Technology by Region after 20 Years

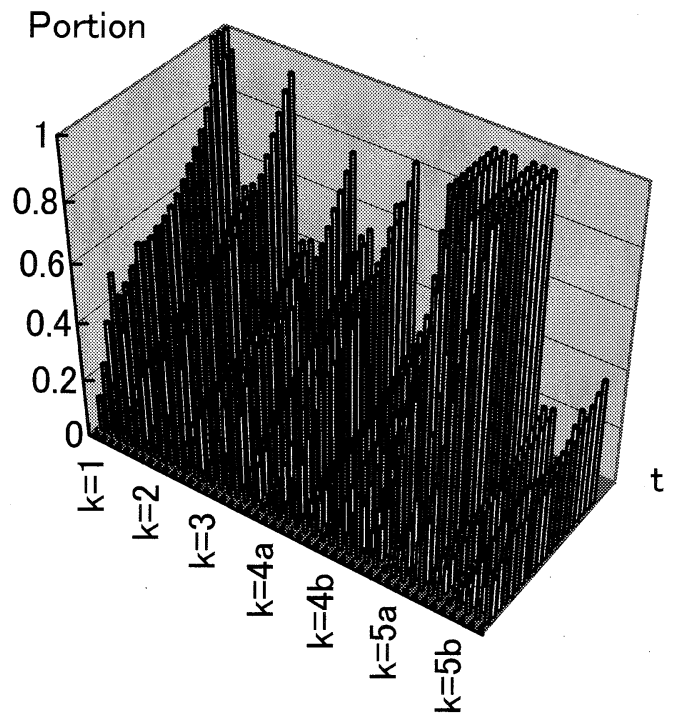

Figure 3 Introduction Rate of Different Desulfurization Technology by Region and Year 
technology. In terms of technology's introduction speed, technology 5a seems super fast. By technology $5 \mathrm{a}$, region 5 and region 7 need less than 10 years; region 1 , region 2 and region 6 need more than 12 years, region 3 needs 20 years; but in region 4, after 20 years, the desulfurization technologies' introduction rate can only reach 75\%. By technology 1 and technology 2, only region 7's introduction rate can reach $100 \%$ within 20 years, and technology 1's speed always shows faster than technology 2. Compared with technology 4a and technology 3 , only after 7 years, technology 4 a's introduction rate becomes higher; such phenomenon is especially obvious in region 1 , region 2 , region 5 , and region 6 . According to the detailed simulation result, the sequence of desulfurization technology whose introduction rate shows higher is : technology 5 a, technology 1 , technology 2 , technology 4 a, technology 3 , technology $4 \mathrm{~b}$, and technology $5 \mathrm{~b}$.

\subsection{Environmental Impacts}

The obvious impact we can expect is emission factors of secondary energy sector can be reduced by year. As shown in figure 4, for all these seven regions, using technology 5 a can make the emission factor be most reduced after 20 years ; on the contrary, by technology $5 \mathrm{~b}$, the emission factor will be least reduced, which means whether its by-products can be sold has very different effects. The sequence of desulfurization technology that can make the emission factor be reduced more is: technology $5 \mathrm{a}$, technology $4 \mathrm{a}$, technology 2 , technology 1 , technology 3 , technology 4b, and technology 5b. Further examining the emission factor of secondary energy sector over twenty years, it shows the speed of emission factor's reduction is quite different by technology. For example, using technology 5 a can make each region's emission factor be reduced most rapidly, while technology 5b's effect seems most unobvious. In addition, region 1's environmental burden seems lightest, since its emission factor becomes lowest, while region 3, region 4's emission factors remain high. In these heavily polluted regions, only technology 5a's environmental impact seems ideal; therefore it is necessary to investigate whether technology 5a's by-product can have good market in these regions. Otherwise, special subsidies need to be considered in these regions. Region 7 is undeveloped region, but its emission factor is highest because it produces high sulfur content coal. Technology 1 , technology $4 \mathrm{~b}$, and technology $5 \mathrm{~b}$ cannot effectively reduce emission factor in

Unit: $\mathrm{SO}_{2}$-ton $/ 10^{6}$ Yuan

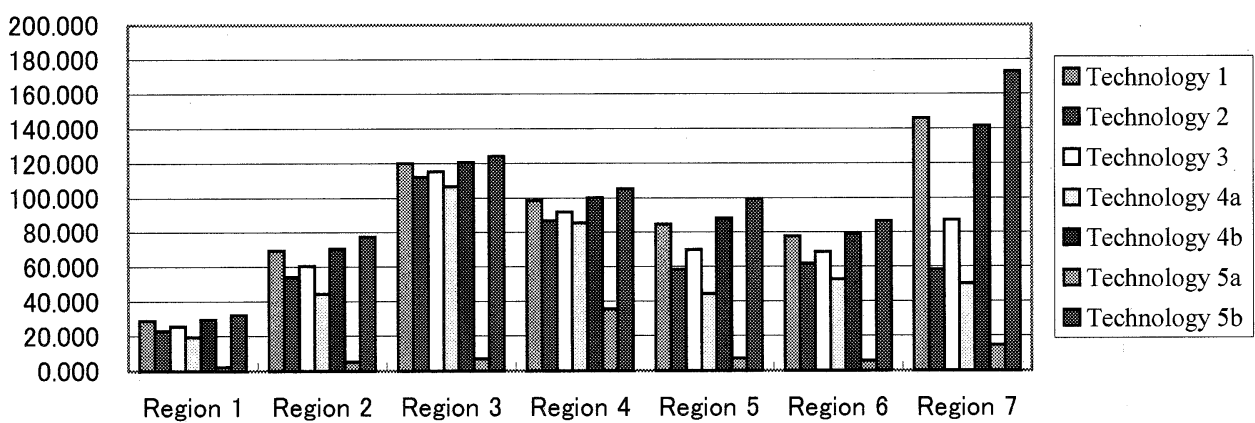

Figure 4 Emission Factors of Secondary Energy Sector by Region after 20 Years 
this region.

\subsection{Economic Effects}

As described above, compared with base case, emission factor of secondary energy sector shows going down. But in other industrial sectors, the emission factors are assumed to be unchanged. It directly results secondary energy sector can pay less sulfur tax than other industries after introducing desulfurization technologies. Therefore, in each year, secondary energy's price becomes lower compared with base case, while other industries' price becomes higher. As shown in figure 5, the sequence of technology that can make secondary energy's price decrease more is : technology $5 \mathrm{a}$, technology $4 \mathrm{a}$, technology 2 , technology 3 , technology 1 , technology $4 \mathrm{~b}$, and technology $5 \mathrm{~b}$. For each technology, the sequence of secondary energy's price decreasing by region is almost same, that is: region 7 , region 6 , region 2 , region 5, region 4, region 1, and region 3. The only exception is technology 5a. For technology 5a, such sequence is : region 6 , region 2 , region 7 , region 4 , region 5 , region 1 , and region 3 . Since compared with other technologies, technology 5a's effect is quite more obvious in every region, after 12 years, the sulfur taxes cannot be fully spent only by installing desulfurization facilities in most regions. According to the detailed simulation result, for each desulfurization technology, the sequence of industry whose price increases more is : commerce, agriculture, service, material, construction, processing, transportation and primary energy. The

Unit: \%o

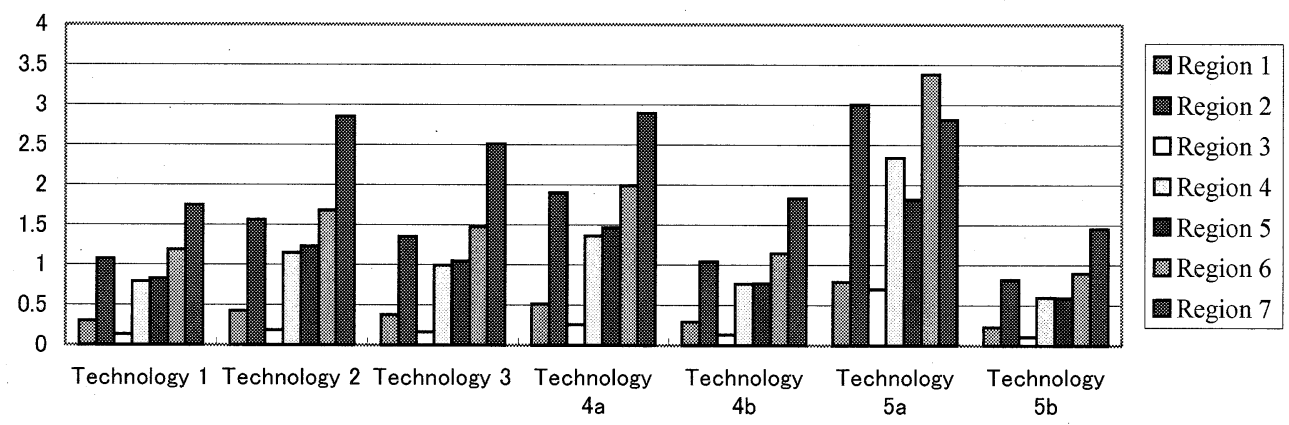

Figure 5 Decreasing rate of secondary energy's price by region after 20 years

Unit: \%o

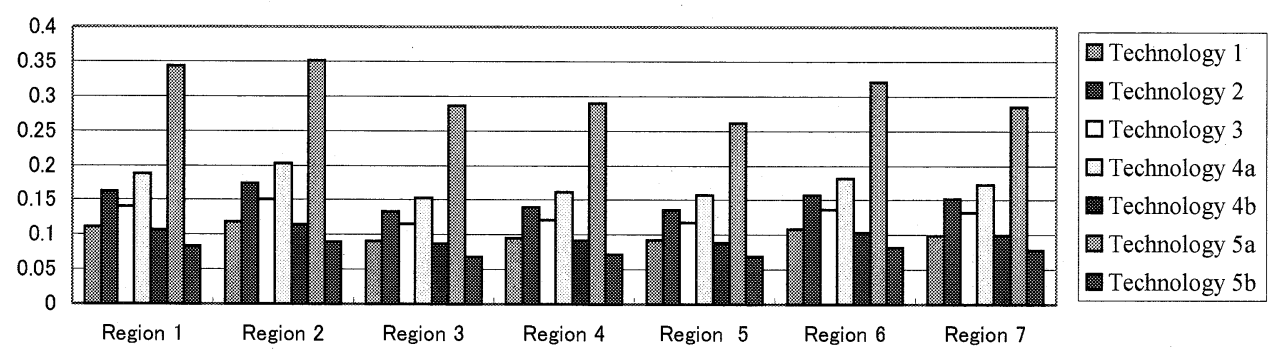

Figure 6 Changing rate of production by region after 20 years 
Unit: \%o
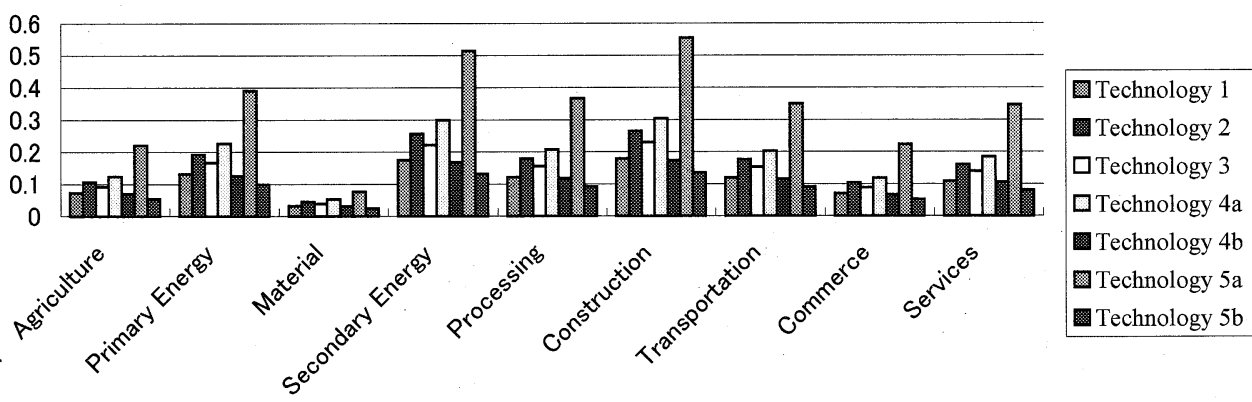

Figure 7 Changing rate of production by industry after 20 years

Unit: \%o
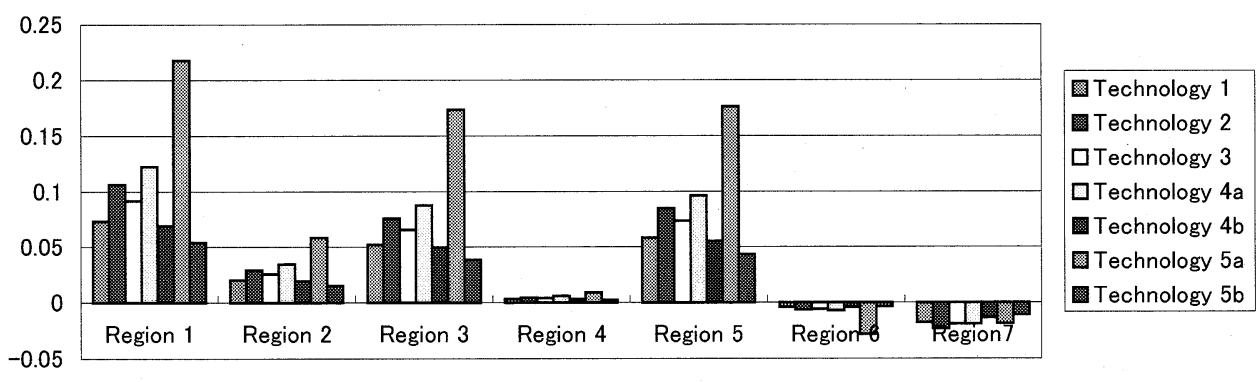

Figure 8 Changing rate of consumption by region after 20 years

reason is some sectors, such as commerce sector and agriculture sector, need less secondary energy inputs than other sectors, and secondary energy's price going down has less effect on these sectors.

Compared with base case, after introducing desulfurization technology, the total production in each region and in each industry after 20 years becomes increasing, as showing in figure 6 and figure 7. Especially, the production of construction sector and secondary energy sector seems increasing more than other sectors. The sequence of technology that can make production increase more is: technology $5 \mathrm{a}$, technology 4a, technology 2, technology 3 , technology 1 , technology $4 \mathrm{~b}$, and technology 5b. As depicted in figure 8 and 9 , after introducing desulfurization technology, the total consumption of region 6 and region 7 decreases while other regions' consumption increases because of interregional transaction. Compared with base case, increasing rate of consumption in secondary energy sector becomes higher than other industrial sectors, since secondary energy sector's price becomes lower. In agriculture and commerce sectors, as described above, their price is increasing more than base case, therefore consumption of these two sectors shows decreasing.

Compared with base case, the regional GDP appears increasing in every region because of production increasing, as showing in figure 10. The sequence of technology that makes GDP increasing is: technology $5 \mathrm{a}$, technology $4 \mathrm{a}$, technology 2 , technology 1 , technology 3 , technology $4 \mathrm{~b}$, and technology $5 \mathrm{~b}$. Among all these regions, region 3's GDP increasing rate 


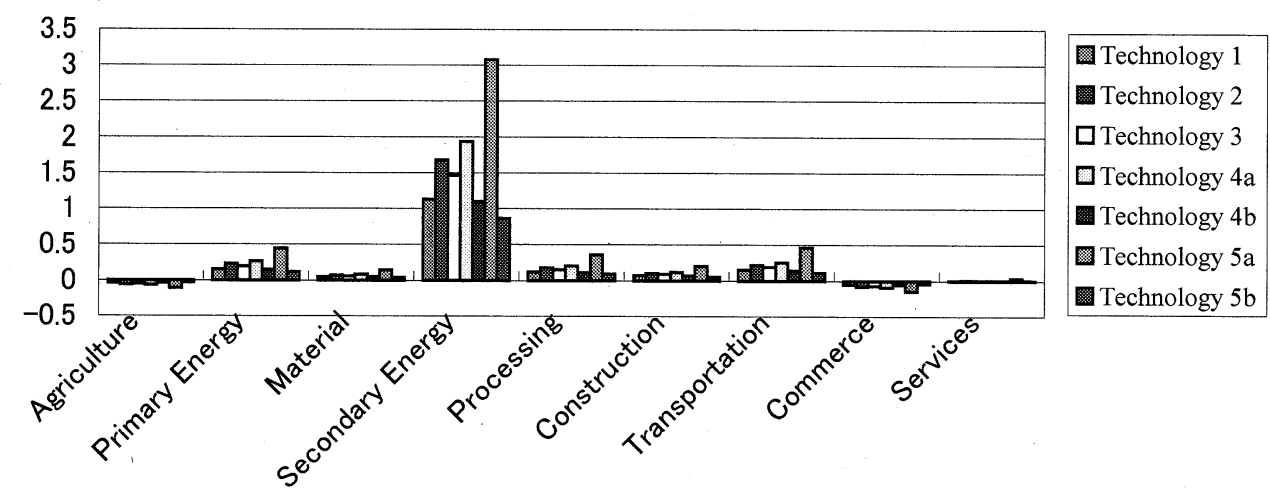

Figure 9 Changing rate of consumption by industry after 20 years

Unit: \%o

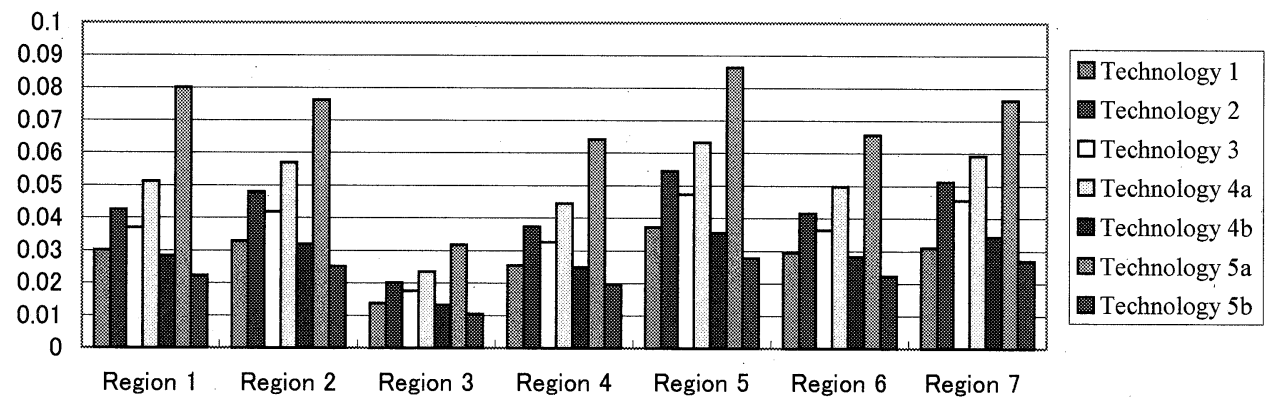

Figure 10 Increasing rate of GDP by region after 20 years

is lowest while region 5's GDP increasing rate is highest, because of interregional transaction.

\section{Conclusion}

In terms of technology's affordability, the sequence of preferable desulfurization technology is: technology $5 \mathrm{a}$, technology 1 , technology 2 , technology $4 \mathrm{a}$, technology 3 , technology $4 \mathrm{~b}$, and technology $5 \mathrm{~b}$. In terms of economic and environmental benefits, the sequence of preferable desulfurization technology is: technology 5a, technology $4 \mathrm{a}$, technology 2 , techno$\log y 1$, technology 3 , technology $4 \mathrm{~b}$, and technology 5b. Moreover, in those comparative developed regions, such as region 3 (Huadong) and region 4 (Huanan), only using sulfur tax to introduce desulfurization technologies in secondary energy sector seems not enough, other subsidies should be inputted to introduce desulfurization technologies.

However, there still remain several points need to be further improved in the future. About technology 4 ( LstWG) and technology 5 (PAFP), we still need to investigate whether their by-products can have market within the local region, and estimate how much proportion of their by-products can be sold. Besides, we have not yet considered the continuing dropping of energy intensity in China's economy. Furthermore, all these data used in this 
study seems out-of-date. How to simulate the mid-term and the long-term energy scenarios is also a problem. Finally, the feasibility to implement environmental tax in China is considered to be an important social problem which needs to be studied in the future.

\section{References}

[1] Burniaux, Jean Marc, et al., "A Multi-region Dynamic General Equilibrium Model for Quantifying the Costs of Curbing $\mathrm{CO}_{2}$ Emissions : a Technical Manual", OECD Working Papers, No. 116, 1992.

[2] Chen, Zili, Studies on the Energy Demand/Supply in China's Economy (in Japanese), Ph.D. Dissertation, Toyohashi University of Technology, 1999.

[3] Liu, MuTing, "Raising Fund for Desulfurization in China Must Shed the Plan Economy Mold" (in Chinese), Environmental Economy, No. 1, 2000, pp. 37-39.

[4] Miyata, Yuzuru, Shibusawa, Hiroyuki, and Li, Aijun, "Interregional Analysis of Environmental Tax on Sulfur Dioxide Emissions in China", Environment and Humanity, Vol. 8, 2003, pp. 50-64.

[5] Su, Huifen, "Choice of Desulfurization Technology's Implementing Scheme for China's Thermal Power Plant" (in Chinese), Electrical Technology, No. 8, 1992, pp. 85-92.

[6] Xie, Yusheng, "Countermeasures for the Acid Rain in China and the Global Environment" (in Japanese), Information on Utilization Technology of Coal, June, 2000, pp. 8-12.

[7] Wan, Zhixuan, "Present Situation of Charges on Pollution Discharges of Thermal Power Plants and Some Proposals on Improvement of the Charging System" (in Chinese), Chinese Electric Power, Vol. 33, No. 1, 2000, pp. 77-81. 